\title{
STUDY OF BEHAVIOUR OF COMPOSITE BEAMS WITH TRUSS TYPE SHEAR CONNECTOR
}

\author{
S. Dhanush ${ }^{1}$, K. Balakrishna Rao ${ }^{2}$ \\ ${ }^{\text {I}}$ Post Graduate Student, Structural Engineering, Department of Civil Engineering, Manipal Institute of Technology, \\ Manipal, India \\ ${ }^{2}$ Professor, Department of Civil Engineering, Manipal Institute of Technology, Manipal, India
}

\begin{abstract}
Composite action of two concrete members is achieved by the interface shear transfer between the two members; this mechanism is of great significance. The interface shear carrying capacity is dependent on the surface properties and shear connectors provided. In the current research ATENA is used, it is FEM based software in which the interface properties between materials can be modeled to a great level of detail. In the present study the influence of angle of inclination, size and the depth of embedment of truss connector on the load carrying behavior is studied with the help of a beam model. The angles of inclination varied are $30^{\circ}, 45^{\circ}, 60^{\circ}$ and $75^{\circ}$ with varying bar diameters of $8 \mathrm{~mm}, 10 \mathrm{~mm}$ and $12 \mathrm{~mm}$. Angles between $60^{\circ}$ to $75^{\circ}$ are found most efficient with no significant changes when diameters are varied. The ultimate load for a given connector is found to be independent of the depth of embedment. Composite beams are also modeled to study the influence of cohesion and friction coefficient, and are compared with behavior of solid and non-composite beams.
\end{abstract}

Keywords: Truss shear connector, Composite slab, ATENA, Slab flexure test, Interface shear capacity

\section{INTRODUCTION}

In view of infrastructure requirements across the country and the emphasis for accelerating construction of bridges with a view to reduce total construction time and minimize traffic disruption, the fast construction of bridges using precast segmental concrete-concrete composite construction has assumed significance. In such a scenario, precast stayin-place deck panels would eliminate the need for form work and staging which are main causes for traffic disruptions. The remaining portion of the deck slab can be cast in place. Precast slab that acts initially as a formwork is connected compositely with in-situ concrete segments using shear connectors in order to develop the required bending and shear resistance resulting in composite slab.

In order for the composite slabs to exhibit monolithic behaviour, the composite interface bond must remain intact. If the bond is strong, the composite member will behave as a single member when loaded and deform similar to a solid member. The fully bonded interface lets the horizontal shear developed to be transferred along the interface. The complete composite behaviour is shown in strains varying almost completely linear across the depth of the slab as shown by the solid line in Figure. 1(c). When the action is not monolithic each layer acts independently represented by the dotted line in figure $1(\mathrm{c})$.

The interface shear transfer is governed by shear connectors which provide a connection between the two slabs. These shear connectors are embedded into each concrete slab and attached to the tensile reinforcement provided in the slab or can be welded in case of steel beams.
The transfer of shear occurs through tension and compression forces along the diagonals of the connectors.

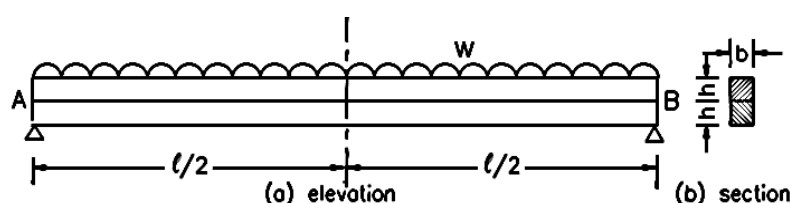

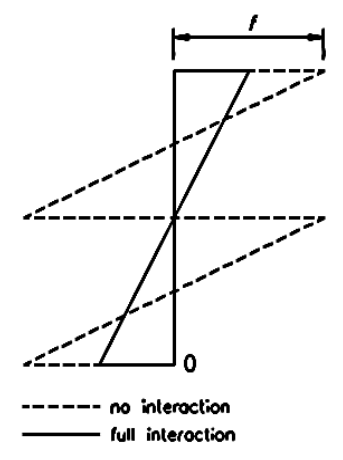

(c) bending stress

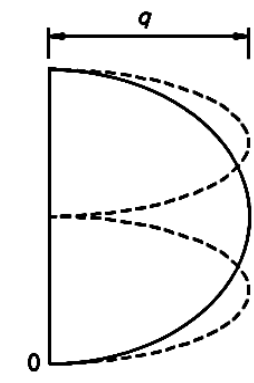

(d) sheor stress
Fig 1 Behaviour of composite beam

The strength of a shear connector should be high enough to prevent any progressive bond slip from taking place. The presence of shear connectors makes the section much stiffer and achieves stronger composite action. The shear connectors primarily resist tensile forces required to maintain the integrity of the units by keeping them attached. Shear connector needs to have sufficient ductility to perform adequately. 
Benoyane et al ${ }^{[1]}$ (2008) studied the flexural behaviour of pre-cast concrete sandwich composite panel having truss type shear connector. The flexural test results showed that the precast specimens had a load deflection profile similar to that of one way and two way slab. The difference in load is less than $4 \%$, when finite element result is compared to experimental result of one way specimen. The difference in deflection during elastic stage is less than $1.5 \%$. Therefore, Finite element studies of the flexure test correlated with the experimental values. Finite element studies were carried out by varying number of shear connectors for the one way slab specimen. It was observed that increasing the number of shear connector increases the ultimate load of the specimen.

Thanoon et al ${ }^{[2]}$ (2010) studied the structural behaviour of ferrocement and brick composite slab panel. The slab is made of two layers (precast ferrocement and brick mortar) joined together using truss connectors. The slab was simply supported and two line loads were created by applying load through hydraulic jack. The ductility ratios were observed to be more than 2 . The peak load is about $30 \%$ of the ultimate load. The concrete rib enhances the ductility of the slab. The specimen with triple shear connector showed higher experimental load. The increase in the number of shear connector increased the compositeness, thereby increased the load carrying capacity of the member

Bush and Stine ${ }^{[3]}$ (1994) studied the flexural behaviour of precast concrete sandwich panel with continuous truss connectors in which two series were tested. Precast concrete sandwich panels were constructed to achieve up to 100 percent composite action, depending on the ability of the embedded connectors to transfer the shear generated by longitudinal flexure. A specimen for cyclic loading was constructed with a few modifications, the loaded panel was simply supported and subjected to three point loading. Since the study focused on flexural behaviour, no axial load applied to the test panels. The intent was to fully force the truss girder to fully participate in order to obtain information on their contribution towards panel stiffness and shear transfer between the wythes. The panel exhibited composite action similar to that of a full depth panel.

Gowthami ${ }^{[5]}$ (2014) studied the effects of different types of shear connectors on one way and two way composite slabs and found that two way slabs take much higher loads compared to one way slabs for a given configuration of shear connectors and that diameter of the bars does not have much of a difference in the results of a one way slab, but shows certain effects in the load carrying capacities of a two way slab.

\section{NON LINEAR FINITE ELEMENT ANALYSIS:}

ATENA, a nonlinear finite element analysis software was employed to analyze the flexural load carrying capacity of the composite slabs. In ATENA, the interface parameters between materials can be modeled to a great level of detail, which would help replicate the field test conditions as far as possible $\mathrm{e}^{[4][6]}$; making the results more acceptable. Numerical analysis would be very much helpful, to simulate the experimental results. It helps to reduce the number of experiments to be conducted.

In ATENA, steel plates are used as bearings where there is a need to apply loads and supports, this is to eliminate the influence of localization of stresses at immediate region under the point of application. The mesh size adopted is 50 $\mathrm{mm}$ and brick elements are used for concrete modeling, whereas tetrahedral elements are used for steel plates. The type of solution adopted is modified Newton-Raphson method, to optimize the node numbers Sloan iterations are used. The stiffness used is the tangent stiffness and the values of the stiffness is updated after each iteration. The number of iterations under each load step is limited to 40 .

The models are analyzed under load controlled method, the post peak behaviour is not studied. Displacement controlled analysis is not performed.

\subsection{ATENA Default Formulae}

\begin{tabular}{|l|l|}
\hline Cylinder strength & $f^{\prime}{ }_{c}=-0.85 f^{\prime}{ }_{c u}$ \\
\hline Tensile strength & $f^{\prime}{ }_{{ }}=0.24{f^{\prime}}^{2} / 3$ \\
\hline Initial elastic modulus & $E_{c}$ \\
\hline Poisson's ratio & $v=0.2$ \\
\hline Softening compression & $\mathrm{w}_{\mathrm{d}}=-0.0005 \mathrm{~mm}$ \\
\hline Compressive strength in & $\mathrm{c}=0.8$ \\
\hline Tension stiffening stress & $\sigma_{\mathrm{st}}=0$ \\
\hline Fracture energy & $G_{f}=0.000025{f_{t}^{\prime}}_{t}[\mathrm{MN} / \mathrm{m}]$ \\
\hline
\end{tabular}

\subsection{Material Modeling}

The input properties for the different materials are as described below:

\subsubsection{Concrete}

Concrete is modeled as 3D-Nonlinear cemetitious material, with the following properties

\begin{tabular}{|l|l|}
\hline Cube Strength $\left(\mathbf{f}_{\mathbf{c u}}\right)$ & $30 \mathrm{MPa}$ \\
\hline Elastic modulus $(\mathbf{E})$ & $3.032 \times 10^{4} \mathrm{MPa}$ \\
\hline Poisson's ratio(m) & 0.2 \\
\hline Tensile strength & $2.317 \mathrm{MPa}$ \\
\hline Compressive strength & $-25.5 \mathrm{MPa}$ \\
\hline Specific weight $(\boldsymbol{\rho})$ & $23 \mathrm{kN} / \mathrm{m}^{3}$ \\
\hline Coefficient of thermal expansion( $\boldsymbol{\alpha})$ & $1.2 \times 10^{-5} / \mathrm{K}$ \\
\hline
\end{tabular}

\subsubsection{Steel}

Steel plates are used as bearings under supports and loads only. It is modeled as a 3D-elastic-isotropic material, with following properties

\begin{tabular}{|l|l|}
\hline Elastic modulus (E) & $2 \times 10^{5} \mathrm{MPa}$ \\
\hline Poisson's ratio(m) & 0.3 \\
\hline Specific weight $(\boldsymbol{\rho})$ & $78.5 \mathrm{kN} / \mathrm{m}^{3}$ \\
\hline
\end{tabular}




\subsubsection{Reinforcement}

Reinforcement bars are modeled as reinforcement elements with bilinear, elasto-plastic behaviour, with the following properties

\begin{tabular}{|l|l|}
\hline Elastic modulus $\mathbf{E}$ & $2.1 \times 10^{5} \mathrm{MPa}$ \\
\hline Yield strength $\left(\mathbf{f}_{\mathbf{y}}\right)$ & $415 \mathrm{MPa}$ \\
\hline Specific weight $(\boldsymbol{\rho})$ & $78.5 \mathrm{kN} / \mathrm{m}^{3}$ \\
\hline Coefficient of thermal expansion $(\boldsymbol{\alpha})$ & $1.2 \times 10^{-5} / \mathrm{K}$ \\
\hline
\end{tabular}

\subsubsection{Concrete-Concrete Interface}

The interface region between the two concrete elements is modeled using 3D-interface model with following properties

\begin{tabular}{|l|l|}
\hline Normal stiffness & $2 \times 10^{5} \mathrm{kN} / \mathrm{m}^{3}$ \\
\hline Tangential stiffness & $2 \times 10^{5} \mathrm{kN} / \mathrm{m}^{3}$ \\
\hline Cohesion & 0 \\
\hline
\end{tabular}

\subsection{Geometric Modeling}

To optimize the size, i.e. diameter, angle of inclination and depth of embedment of the shear connectors, a beam model of size $150 \mathrm{~mm} \times 150 \mathrm{~mm} \times 1000 \mathrm{~mm}$ is used instead of a full slab. This is done because modeling and analysis of a full slab for all the above mentioned objectives would take up a lot of computational time and space.

\subsubsection{Beam Model}

The beam size chosen for the study has cross section dimensions of $150 \times 150 \mathrm{~mm}$ and an effective span of $1 \mathrm{~m}$. The beam is simply supported on either ends and loaded at $1 / 3^{\text {rd }}$ spans to achieve pure flexure. It is reinforced with two bars of $8 \mathrm{~mm}$ at the bottom with an effective cover of $20 \mathrm{~mm}$ and spacing of $110 \mathrm{~mm}$. For the composite section two beams of $75 \mathrm{~mm}$ depth with an interface layer is modeled such that the overall dimensions of both models be same for comparison. The shear connector in the composite beams are provided at the centre with varying depths of embedment when necessary. The load increment is $1 \mathrm{kN}$ per step for all beam models

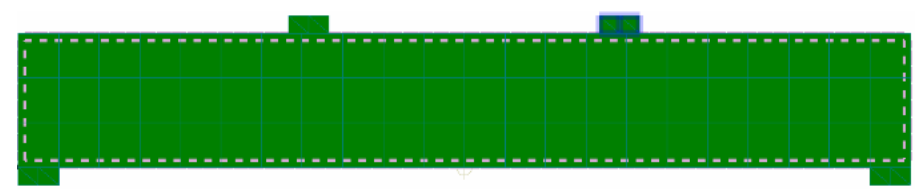

(a)

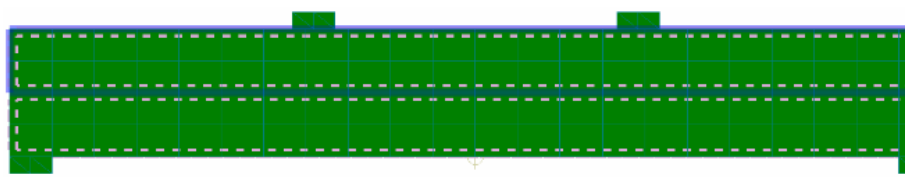

(b)

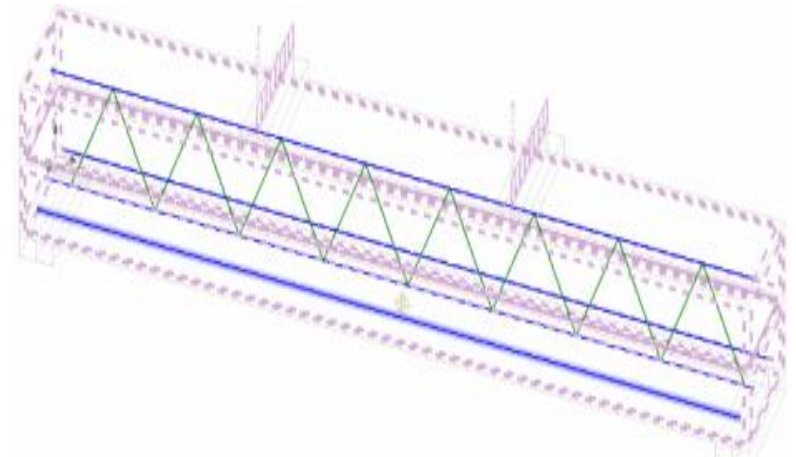

Fig 3 Typical beam showing supports, loading, reinforcements and shear connector

\section{RESULTS AND DISCUSSION}

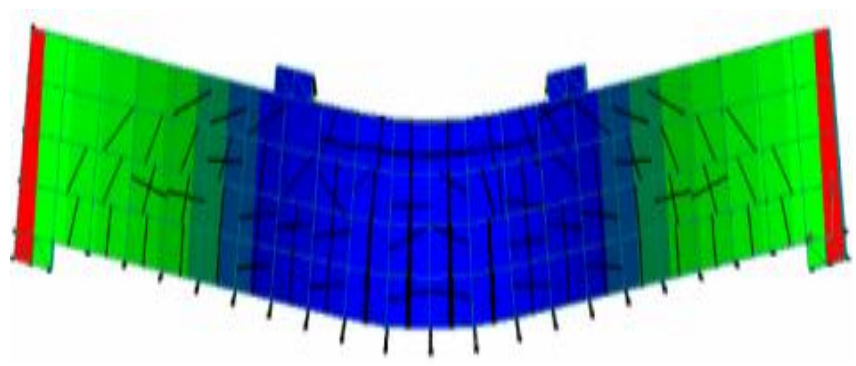

Fig 4 Deflection contour plot for Solid model

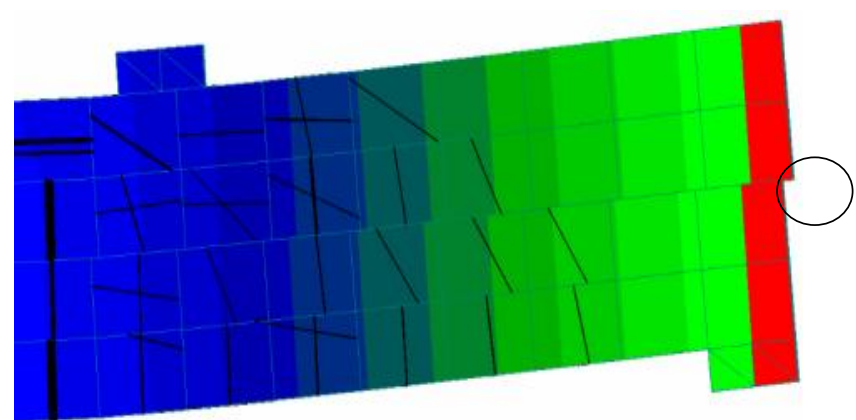

Fig 5 Deflection contour plot for Non-Composite model showing slip at the horizontal interface

To optimize the dimensions of the truss shear connectors i.e. to determine the best possible bar diameter, angle of inclination of truss and depth of embedment the beam model described earlier has been used. Three bar diameters $8 \mathrm{~mm}$, $10 \mathrm{~mm}$ and $12 \mathrm{~mm}$ are modeled for four different angles of inclinations $30^{\circ}, 45^{\circ}, 60^{\circ}$ and $75^{\circ}$. So, a total of 12 models are analyzed to get the angle and bar diameter for which the most composite action is exhibited.

Fig 2 (a) Solid beam (b) Composite beam 


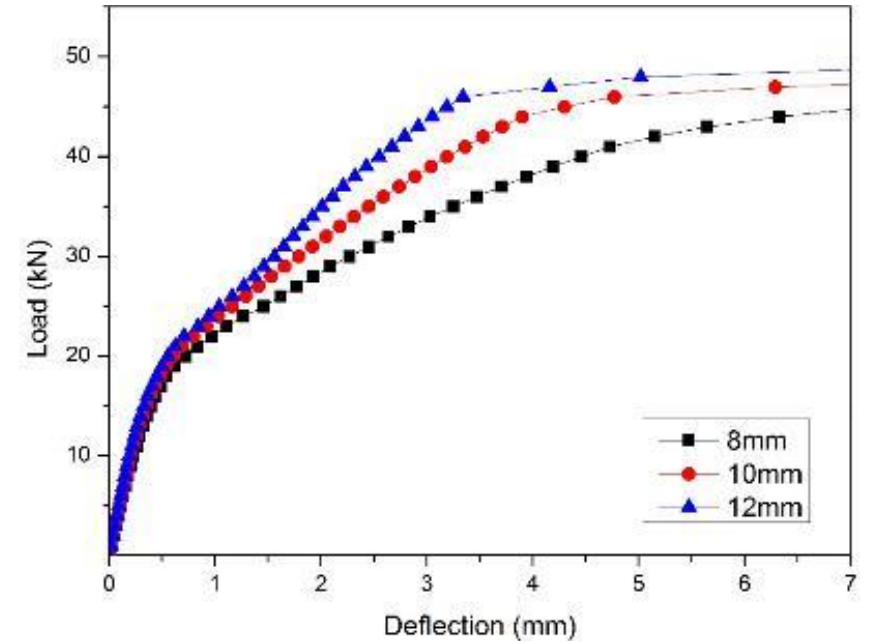

Fig 6 Load v/s Deflection graph for 30o truss

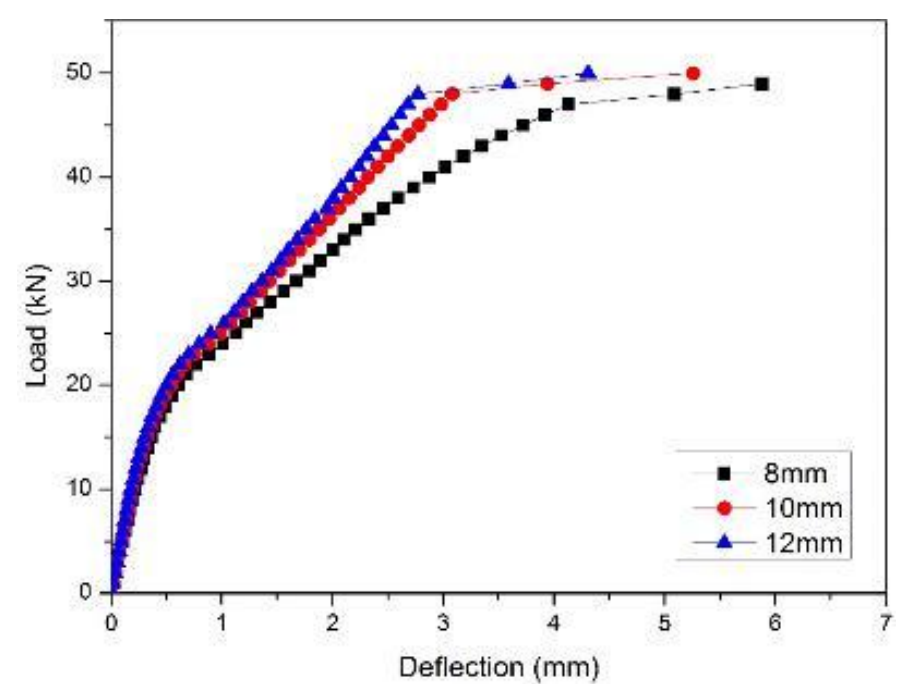

Fig 7 Load v/s Deflection graph for 45o truss

From figures 6, 7, 8 and 9 it can also be seen that for a given angle of inclination when the diameter is varied, there is no significant change in the load carrying behaviour. However, as the percentage of steel increases, there is a slight decrease in the deflection for all models.

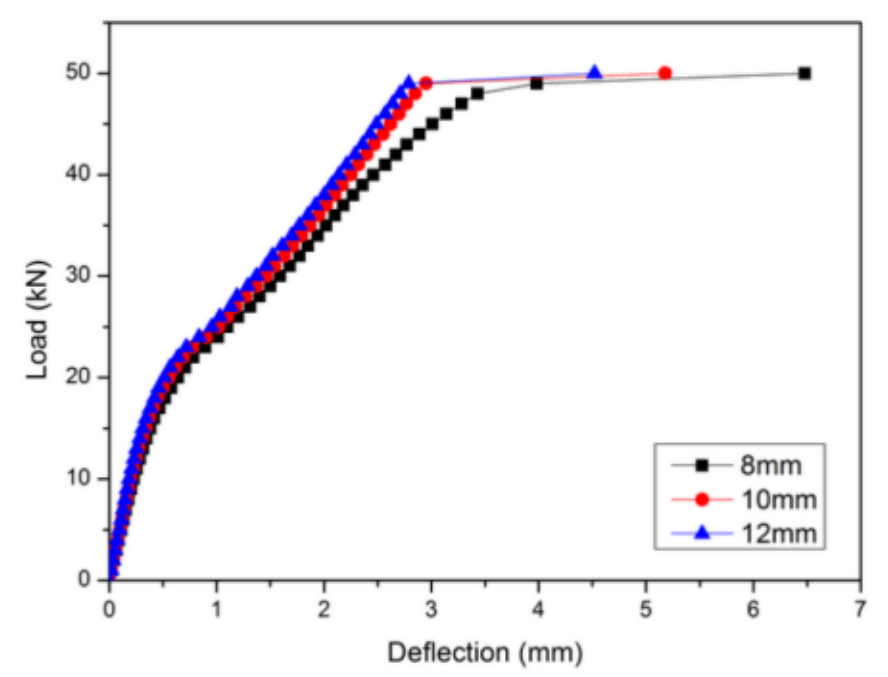

Fig 8 Load v/s Deflection graph for 60o truss

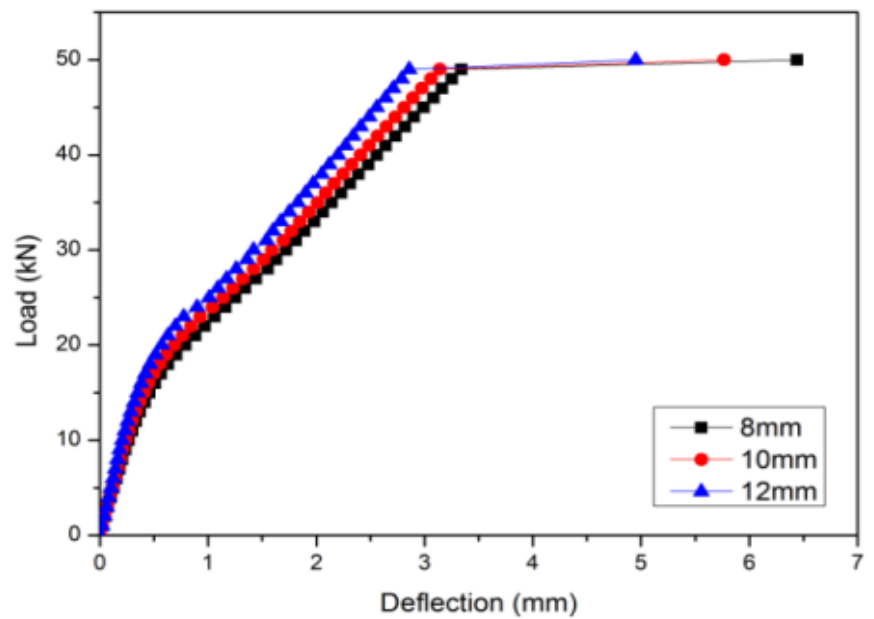

Fig 9 Load v/s Deflection graph for 75o truss

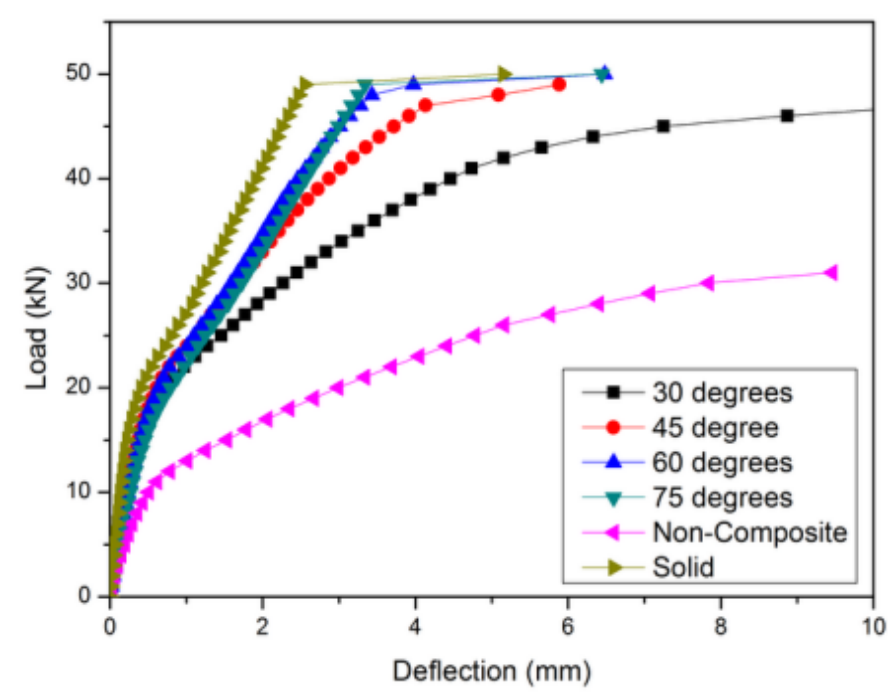

Fig $10 \mathrm{Load}$ v/s Deflection graph for $8 \mathrm{~mm}$ truss

From figures 10, 11 and 12 it is evident that, as the angle of inclination increases the load carrying capacity increases up to $60^{\circ}$, but beyond that there is no significant change. And since $60^{\circ}$ will require less steel than $75^{\circ}$ without compromising on efficiency.

This is because, at $60^{\circ}$ the angle of steel provided gives sufficient bondage for monolithic action and any increase in the percentage of steel beyond this, there is no significant change. 


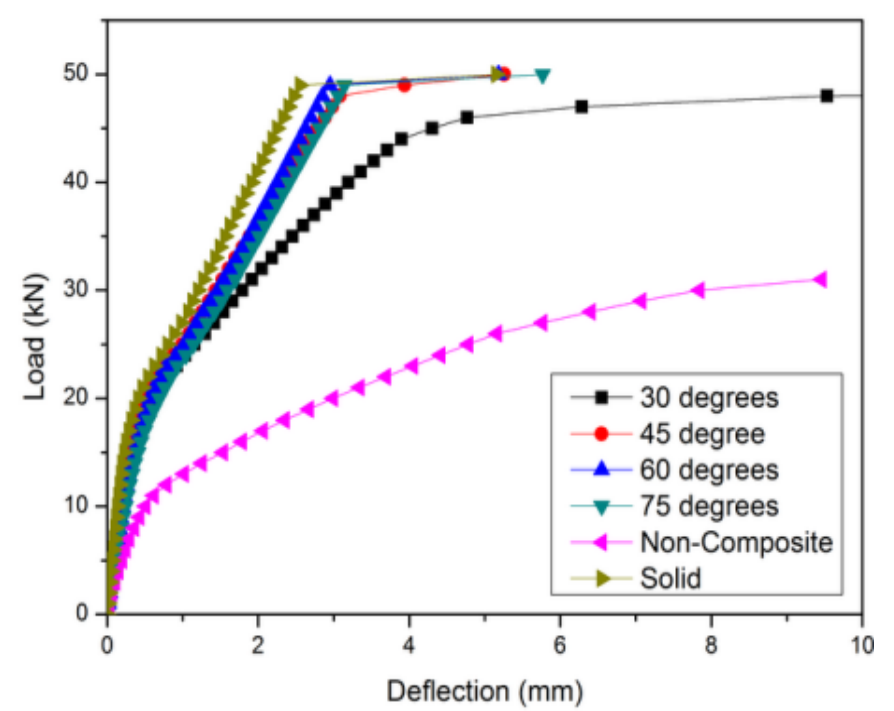

Fig $11 \mathrm{Load}$ v/s Deflection graph for 10mm truss

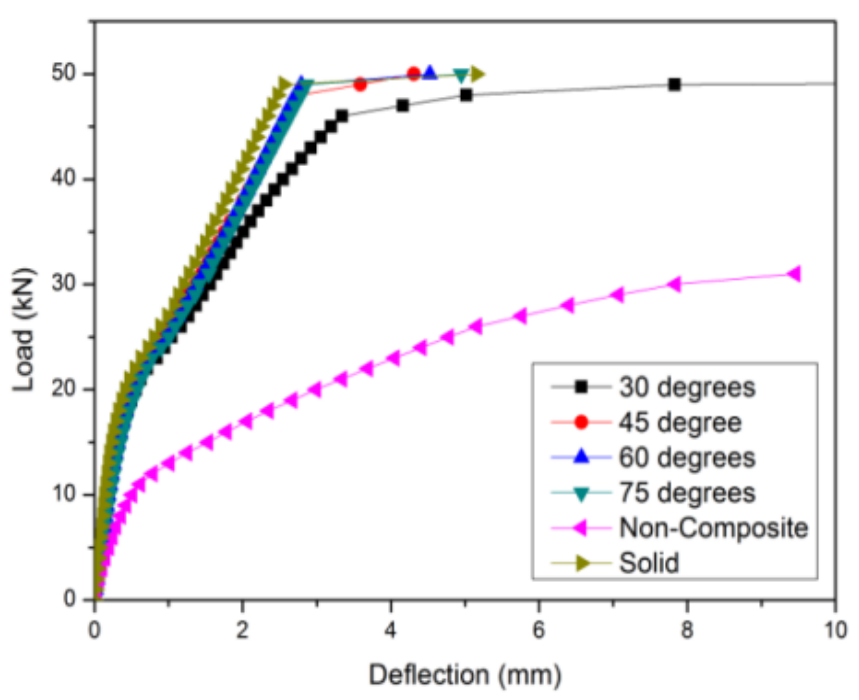

Fig 12 Load v/s Deflection graph for $12 \mathrm{~mm}$ truss

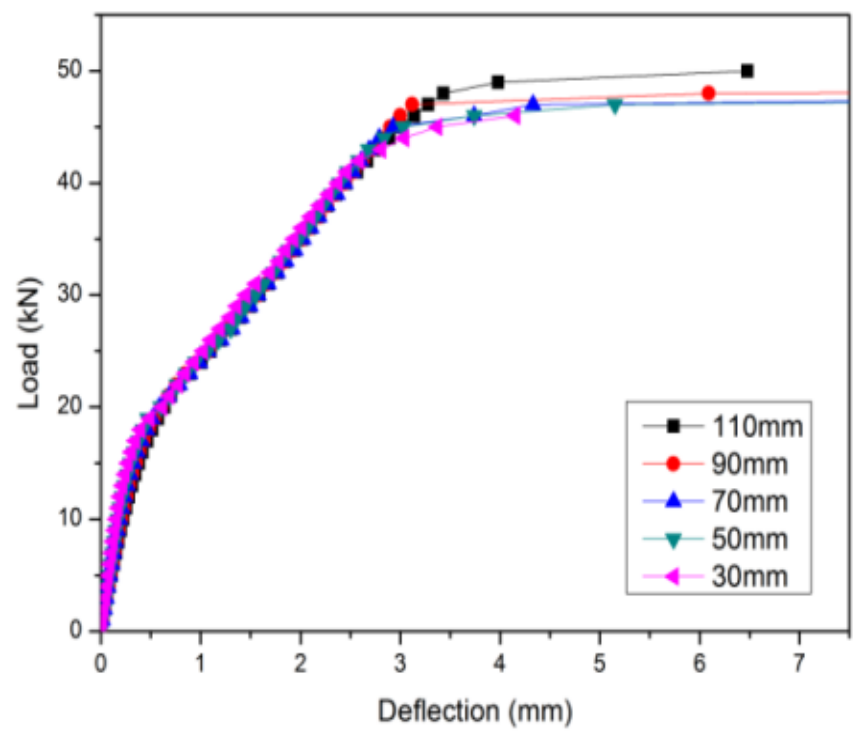

Fig 13 Load v/s Deflection graph for 8mm, 60o truss with different depths of embedment
Using $60^{\circ}$ truss with $8 \mathrm{~mm}$ diameter, beams were modeled with trusses having various depths of embedments and behaviour was observed. The results obtained are plotted in Figure 13. It is observed that, for a given angle of inclination, the load carrying capacity is independent of the depth of embedment. This is because for a given angle of inclination and given span, the area of steel per unit length will remain the same irrespective of the depth of embedment.

All of the above models were analyzed with an assumption, taking value of cohesion and coefficient of friction taken as zero. However, in reality this might not be the case. All the results presented prior to this point are worst case scenarios where the entire behavior depends completely on the shear connector provided. All the results presented hence forth are taking into consideration the influence of cohesion and coefficient of friction.

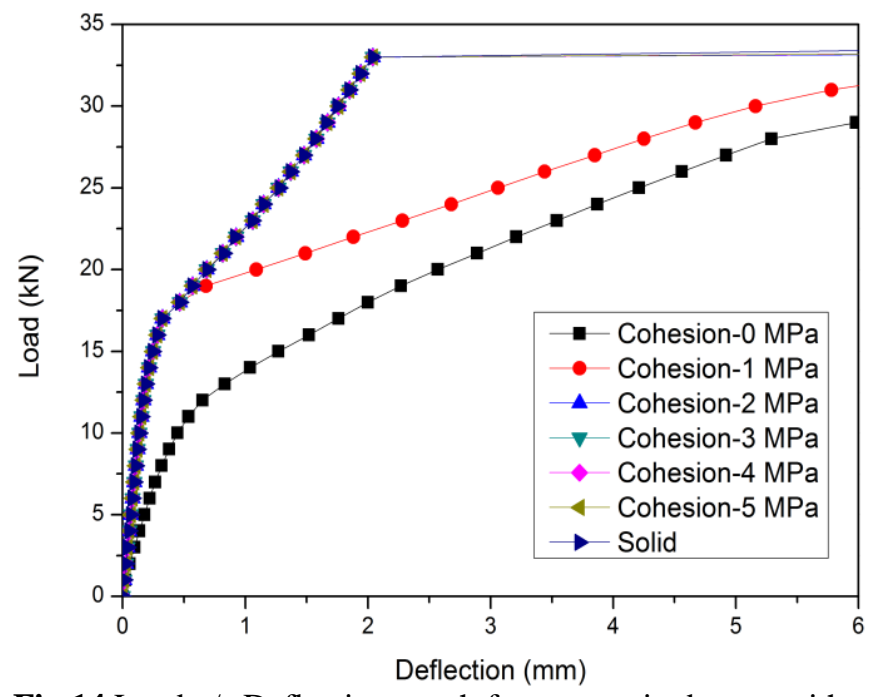

Fig 14 Load v/s Deflection graph for composite beams with varying values of cohesion

Figure 14. gives the load v/s deflection behavior of composite beams with varying values of cohesion at the interface layer, with friction coefficient of 0.4. From the figure it can be seen that the behavior increases as the cohesion value increases upto $2 \mathrm{MPa}$, beyond which there is no change in behavior of the beam. Also, for all values of cohesion for $2 \mathrm{Mpa}$ and above the behavior of the beam is exactly similar to that of a solid beam. Dias-da-Costa ${ }^{[4]}$ arrived at a cohesion value of 4.4 MPa based on experiments performed on push-off specimens. 


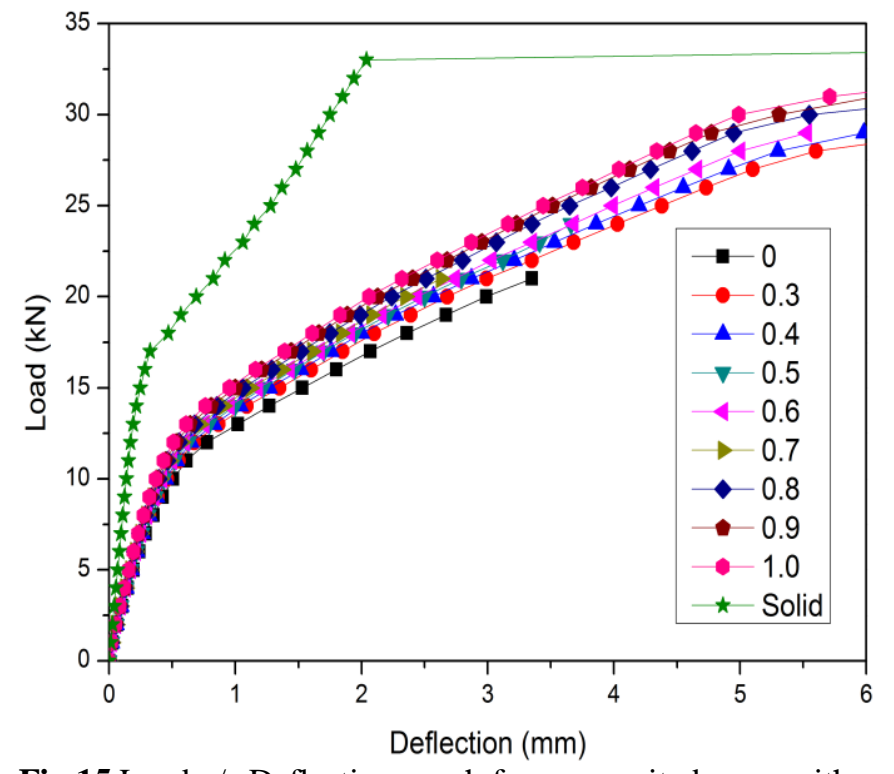

Fig 15 Load v/s Deflection graph for composite beams with varying values of friction coefficient

Figure 15. gives load v/s deflection behavior of composite beams for varying values of friction coefficients keeping cohesion constant at $0 \mathrm{MPa}$. It can be seen from the plot that there is a slight improvement in behavior of the beam as the value of friction coefficient increases. However, even when it is taken to be a maximum of 1 , the behavior is still far from solid beam. Hence it can be concluded that friction coefficient has very less impact on the overall behavior at the interface.

\section{CONCLUSION}

The following are the observations from the present analysis.

a) The load carrying capacity increases as the angle of inclination of the truss connectors up to $60^{\circ}$ beyond which it remains same, this is because at $60^{\circ}$ the area of steel provided is sufficient to ensure monolithic action, anything beyond this, does not make much of a difference.

b) For a given angle of inclination there is no significant change in the behaviour for a change in bar diameter. However as the percentage of reinforcement increases there is a reduction in the deflection.

c) For a given angle of inclination and bar diameter, the behaviour remains the same independent of depth of embedment of the connector. Since, for a given angle of inclination, the area of steel per unit length remains same, irrespective of the depth of embedment.

d) In a slab, shear connectors provided in the transverse direction does no improve the behaviour in any significant way.

e) As the number of connectors in the longitudinal direction is increased, the load carrying capacity of the slab also increases.

f) Transverse connectors when provided with longitudinal connectors influence the load carrying behavior, increasing it slightly. g) Behavior of composite beams increases as the value of cohesion increases up to $2 \mathrm{MPa}$, beyond which the behaviour is similar to that of a solid beam.

h) Behavior of the composite beams increases slightly with increase in the value of coefficient of friction from 0 to 1 . However, even for a maximum value of 1 the behaviour is far from a solid beam.

\section{ACKNOWLEDGMENTS}

The authors would like to express their sincere thanks to The Director, and H.O.D, Civil Engineering, Manipal Institute of Technology, Manipal, for providing necessary facilities required for the present study and also express their deepest gratitude towards the Department of Civil Engineering, BMS College of Engineering, Bangalore, for letting us avail the facilities of the software ATENA.

\section{REFERENCES}

\section{Journal Articles}

[1] Benoyane, A.A. Abdul Samad, D.N. Trikha, A.A. Abang Ali, S.H.M. Ellinna, "Flexural Behavior of pre-cast concrete sandwich composite panel Experimental and theoretical investigations", Construction and Building Materials, 2008, 22, 580592.

[2] Waleed A. Thanoon, Yavuz Yardim, M.S. Jaafar, J. Noorzaei, "Development of interlocking mechanism for shear transfer in composite floor ", Construction and Building Materials, 2010, 24, 2604-2611.

[3] Bush TD, Stine GL, "Flexural Behavior of composite precast concrete sandwich panels with continuous truss connectors", PCI J, 1994, 39, 112-121

[4] Dias-da-Costa .D. Alfaiate .J. Júlio; 'FE modeling of the interfacial behaviour of composite concrete members', Construction and Building Materials, 2012, (26): 233-243.

\section{Books}

[5] N. R. Gowthami, K Ramanjaneyulu "Segmental Composite Bridge Decks", MTech Thesis, JNTU Ananthapur, 2014.

\section{Conference Proceedings}

[6] A Kabir, S M Nizamud-Doulah, M Kamruzzaman, "Effective Reinforcement Layout For Skew Slabs", 27th Conference on our World in Concrete \& Structures: 29 - 30 August 2002, Singapore, PP. 271276, 2002

[7] S. Dhanush , K. Balakrishna Rao, "Truss Type Shear Connectors Used in Segmental Composite Slab", Proceedings of The International Conference on Advances in Civil Engineering Materials and Processes, Coimbatore Institute of Technology, Coimbatore, Jan-2015

[8] S. Dhanush , K. Balakrishna Rao, "Behaviour of Segmental Composite Skew Slabs Subjected to Flexure Loading", Proceedings of The National 
Conference on Technological Innovations for Sustainable Infrastructure, National Institute of Technology, Calicut, March-2015

\section{BIOGRAPHIES}

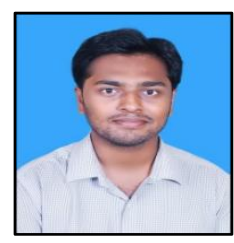

Mr. S. Dhanush is a post graduate student currently pursuing masters in Structural Engineering from Manipal Institute of Technology. He's currently working on segmental composite slabs used as bridge decks

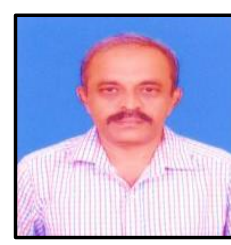

papers.
Dr. K. Balakrishna Rao is a professor of civil engineering at Manipal Institute of Technology, Manipal. He has over 27 years of teaching experience and 10 years of research experience. He has published over 50 conference papers and 6 journal 